\title{
Comprehensive Analysis of the Expression and Prognosis for Laminin Genes in Ovarian Cancer
}

\author{
Bowen Diao and Ping Yang* \\ Department of Gynecology, First Affiliated Hospital, School of Medicine, Shihezi University, Shihezi, China
}

\section{OPEN ACCESS}

Edited by: Anna Sebestyén,

Semmelweis University, Hungary

${ }^{*}$ Correspondence:

Ping Yang

pingy2018@163.com

Specialty section: This article was submitted to, a section of the journal Pathology and

Oncology Research

Received: 26 April 2021 Accepted: 12 August 2021 Published: 25 August 2021

Citation:

Diao B and Yang P (2021)

Comprehensive Analysis of the Expression and Prognosis for Laminin

Genes in Ovarian Cancer. Pathol. Oncol. Res. 27:1609855. doi: 10.3389/pore.2021.1609855
Survival is low in ovarian cancer (OC). Most OC patients demonstrate advanced metastases, and recurrence is common. Dysregulation of laminin interactions is associated with cancer development. However, it is unknown whether laminin subunits can be considered as biomarkers for $\mathrm{OC}$ diagnosis, prognosis, and treatment. We used cBioPortal, GEO, ONCOMINE, GEPIA, Human Protein Atlas, Kaplan-Meier Plotter, TIMER, and Metascape to determine the associations among laminin expression, prognosis, and immune cell infiltration in OC. LAMA5, LAMB3, and LAMC2 mRNAs and LAMA3, LAMB1/ B2/B3, and LAMC1/C2 proteins were overexpressed in OC tissues compared with normal ovaries. LAMA4, LAMB1, and LAMC1 mRNA upregulation was positively correlated with worse overall survival (OS) and progression-free survival (PFS) in OC. Elevated LAMA2 and LAMC2 mRNA expression levels were related to better PFS or OS, respectively. The results speculated that LAMA5 could potentially be a good prognostic factor in OC. Its expression proves valuable for predicting OS in patients diagnosed with stage IV and grade $3 \mathrm{OC}$ and PFS in patients diagnosed with all OC stages or grades. LAMB3 and LAMC2 expression was correlated with platinum resistance development. $R O C$ analysis of laminins in OC sets revealed that LAMA2/A4/A5, LAMB1/B2/B3, and LAMC2 could be used to differentiate between malignant tumors and non-neoplastic tissues. LAMA1/A5 and LAMC1 were significantly and negatively correlated with various tumor immune infiltrates (TILs), especially with dendritic cells, $C D 8^{+} T$ cells or neutrophil. LAMA4 and LAMB1 might be associated with tumor purity in OC. Overall, LAMA5 and LAMC1 could help predict OC survival and diagnosis and might be deemed important OC oncogenes.

Keywords: ovarian cancer, metastasis, laminins, cancer prognosis, bioinformatical analysis

\section{INTRODUCTION}

Ovarian cancer $(\mathrm{OC})$ is the eighth most frequently occurring cancer in women worldwide. There were 384,000 OC-related deaths reported in 2018[1]. The median age of patients diagnosed with OC is approximately 60 years, and most patients present with advanced metastasis[2]. The 5-year survival rates for stages I-IV are $93,68,27$, and $13.4 \%$, respectively [3]. Recurrence is incurable in nearly $75 \%$ of all women presenting with advanced disease[4]. Surgical resection and platinum-based chemotherapy are the primary OC treatment strategies. While most patients exhibit favorable and appreciable responses to first-line chemotherapy, cases relapse within 18 months and patients succumb to the disease[2]. Therefore, it is necessary to develop and establish effective markers for the conduction of early diagnosis, for the formulation of strategies addressing metastasis and 
chemotherapy resistance, and for the discovery of alternatives such as immunotherapy for ovarian cancer.

Previous studies demonstrated the prognostic value of laminins in gastric cancer[5], hepatocellular carcinoma[6], renal cell carcinoma[7], breast cancer[8], colorectal cancer[9], pancreatic cancer, and lung cancer[10]. Laminin is a complex glycoprotein composed of three different polypeptide chains connected by disulfide bonds and is a cross-shaped molecule. Laminins are the chief components of vascular and parenchymal basement membranes and provide structural basis for the extracellular matrix (ECM)[11]. Dysregulated cell laminin interactions are major features of various cancers[11]. Certain members of the laminin gene families are correlated with cancer cell migration and tumor invasiveness. Overexpression of certain laminin chains is associated with cancer progression and poor cancer prognosis[12]. Integrins and nonintegrin molecules are the major cell surface receptors for laminins[13]. At least one laminin gene is detected in approximately half of all ovarian cortical cells. These genes may encode LAMA2/A5, the $\beta$-chains of LAMB1/B2, the $\gamma$-chain of LAMC1, and others[14]. However, it is unclear whether the key subunits of laminin genes can serve as biomarkers for OC diagnosis, prognosis, and treatment. Thus, we designed and executed the present study to address gaps in the existing research and to ascertain the potential applicability of laminin genes in various aspects of ovarian cancer treatment.

\section{MATERIALS AND METHODS}

\section{cBioPortal}

CBioPortal (http://www.cbioportal.org/) is widely used to investigate and visualize multidimensional cancer genomics data[15]. The types of comprehensive gene data in CBioPortal include those pertaining to somatic mutations, DNA copy number changes, mRNA and microRNA expression, among others. A dataset comprising information derived from 307 patients with ovarian serous cystadenocarcinoma contained mRNA data (RNA Seq V2) (TCGA, Firehose Legacy) and was selected to analyze genetic variation. In the present study, mutations, putative copy number alterations from GISTIC, and mRNA expression z-scores (RNA Seq V2 RSEM) were selected for genomic profiles. The data on the relationships between CNA (relative linear copy number) and the mRNA expression of each laminin member were plotted. A KaplanMeier plot provided insights into laminin gene mutations and their relationships with OS and DFS in OC patients. A log-rank test was used to determine the significance of the divergence in the survival curve. When $p<0.05$, divergence was considered significant.

\section{Oncomine Database}

Oncomine (http://www.oncomine.org) is an microarray database of carcinoma and comprehensive platform intended for mining information about cancer genes [16]. Oncomine contains cancer mutation profiles, gene expression data, and relevant clinical information that can be used to identify new biomarkers or therapeutic targets. It combines RNA and DNA-seq data from
GEO, TCGA, and reported literature sources. In our study, we obtained the transcriptional expression of laminins between cancer and relevant ovarian tissues. The differences in transcriptional expression were contrasted with the Student's t-test, and the following parameters were set: $p$-value: 0.01 , fold change: 1.5, gene rank: all, data type: mRNA, analysis type: Cancer vs. Normal analysis.

\section{The GEPIA2 (Gene Expression Profiling Analysis)}

The GEPIA2 (http://gepia2.cancer-pku.cn/) web server is a reference source used for gene expression analyses. It is based on the Cancer Genome Atlas (TCGA) and the Genotype-Tissue Expression (GTEx) databases [17]. In the present study, the threshold of $|\log 2 \mathrm{FC}|$ was 1 , the $p$-value cutoff was 0.05 . Spearman's correlation coefficients were calculated. The function Similar Genes Detection was used to search for genes similar to those encoding laminins.

\section{The Human Protein Atlas}

The Human Protein Atlas (https://www.proteinatlas.org) contains data on nearly 20 types of cancer based on immunohistochemical (IHC) expression[18]. It furnishes tissue and cell distribution information on 24,000 human proteins and is available in the public domain. In the present study, laminin expression in OC and normal tissues was compared via IHC. Antibody names and stain intensities are indicated in the figures.

\section{The Kaplan-Meier Plotter (Ovarian Cancer)}

The Kaplan-Meier plotter database (http://kmplot.com/analysis/) is an analytical prognostic database used for the analysis of malignant tumors. It is used to assess the impact of over 54,000 genes in the prognosis of 21 different types of cancer [19]. In medical training and scientific research, this database is used to explore the relationships between gene expression and tumor prognosis. The Kaplan-Meier plotter bioinformatics analysis platform can be used to inquire into the prognostic value of 12 laminin genes. Based on their median mRNA expression levels, tumor patients were separated into two groups using the Kaplan-Meier plotter and were verified based on K-M survival curves. The risk ratio (HR) and the log-rank $p$-values of the $95 \%$ confidence interval (CI) were used to determine OC patient OS and PFS. $p<0.05$ was considered statistically significant.

\section{TIMER (Tumor Immune Estimation Resource)}

The algorithm in TIMER (https://cistrome.shinyapps.io/timer/) is used to systematically analyze immune cell infiltration in cancer [20]. The associations between each laminin member and massive immune infiltration in $\mathrm{OC}$ were investigated. The immunocytes involved included B cells, $\mathrm{CD} 4^{+} \mathrm{T}$ cells, CD8+ T cells, neutrophils, macrophages, and dendritic cells. Spearman's correlation coefficients were calculated. 


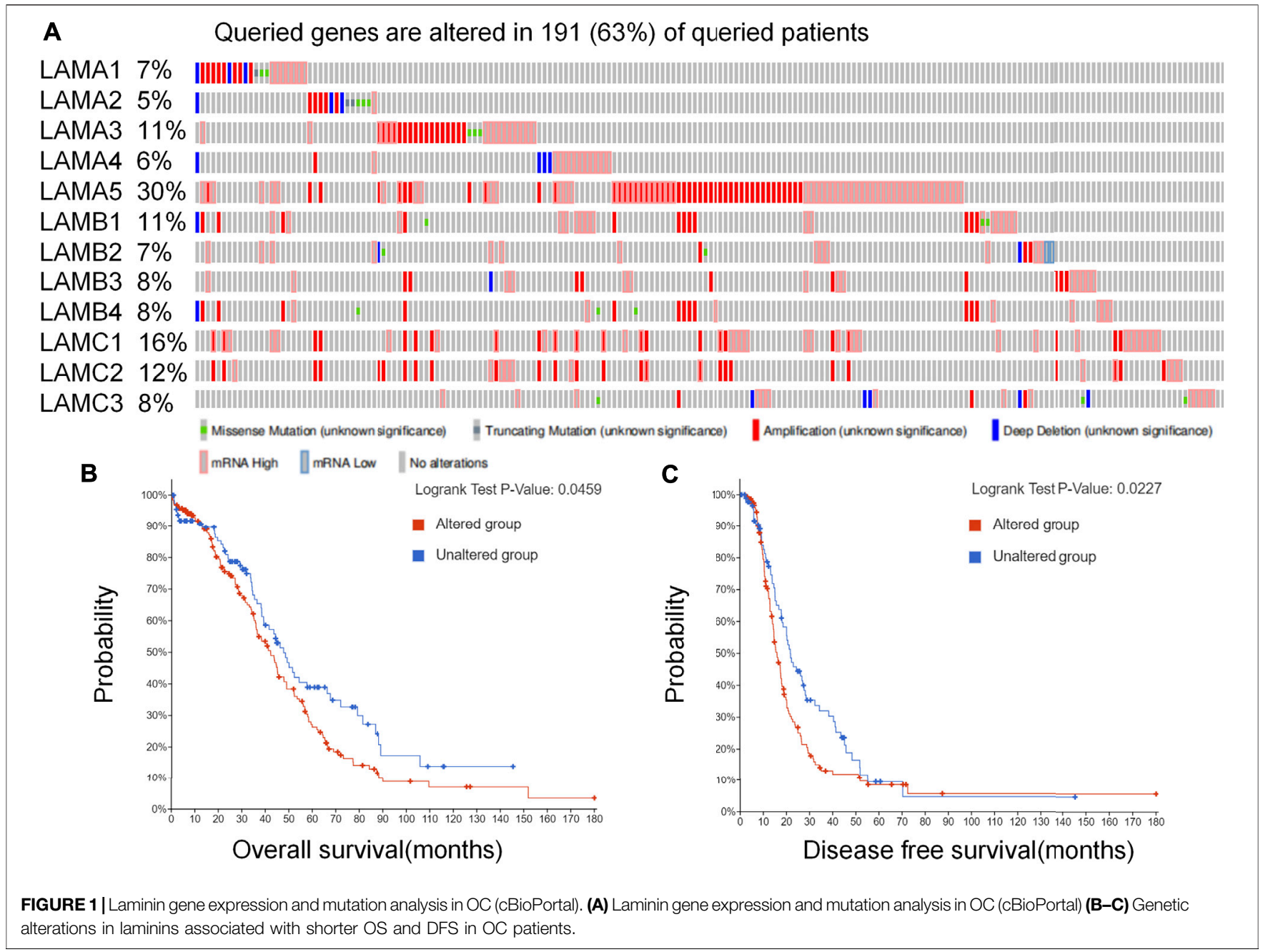

\section{GEO Database and GEO2R}

GEO is a communal functional genomic database, which includes a large number of array and sequence data [21]. The two gene chip profiles GSE131978[22] and GSE58470 datasets [23] were obtained from NCBI-GEO. Users can use GEO2R to compare sets of samples in order to classify disparate genes expressed. In this study, the GEO2R online tools were used to distinguish DEGs (Differential expressed genes) between ovarian tumors and adjacent normal tissues, by the cut-off criteria of adjusted $p<$ 0.05 and $|\log 2 \mathrm{FC}|>1$.

\section{Metascape Analyses}

Metascape is a web-based portal that provides inclusive gene list commentary and analysis resources [24]. We selected 20 genes similar to each laminin-family gene from GEPIA2. To identify the biological functions and pathways of these genes, we used Metascape to analyze Kyoto Encyclopedia of Genes and Genomes (KEGG) pathway enrichment. Gene Ontology (GO) term enrichment analysis was performed to determine the functions of the target host genes in terms of biological process, cell composition, and molecular function.

\section{GeneMANIA and STRING Analyses}

We used the GeneMANIA (http://www.genemania.org/) and STRING (https://string-db.org) [25] databases to explore the gene-gene and protein-protein interaction networks of the laminins. GeneMANIA can use large functionally linked data to identify other genes related to target genes. STRING is used to search for known protein interactions. Interactions revealed by STRING are primarily based on the confidence score (reliability index) as well as other collateral information such as protein domains and three-dimensional protein structures.

\section{RESULTS}

\section{Genetic Mutations in Laminins and Their Associations With Overall Survival and Disease-free Survival in Patients With Ovarian Cancer}

We evaluated genetic alterations in laminins and their relationships with the OS and DFS of OC patients registered 
A

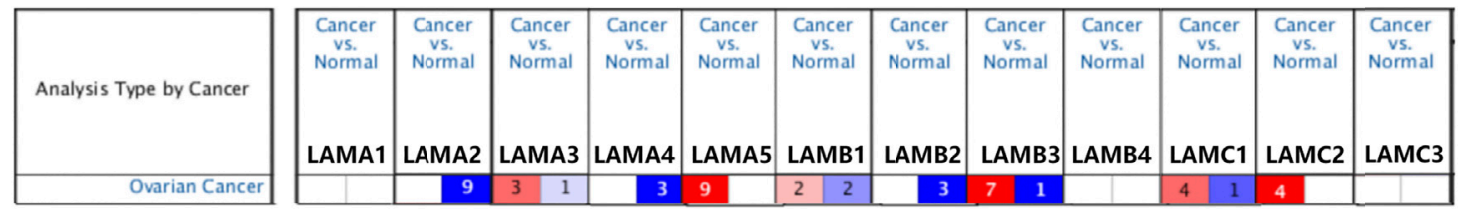

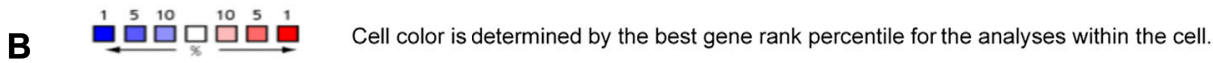
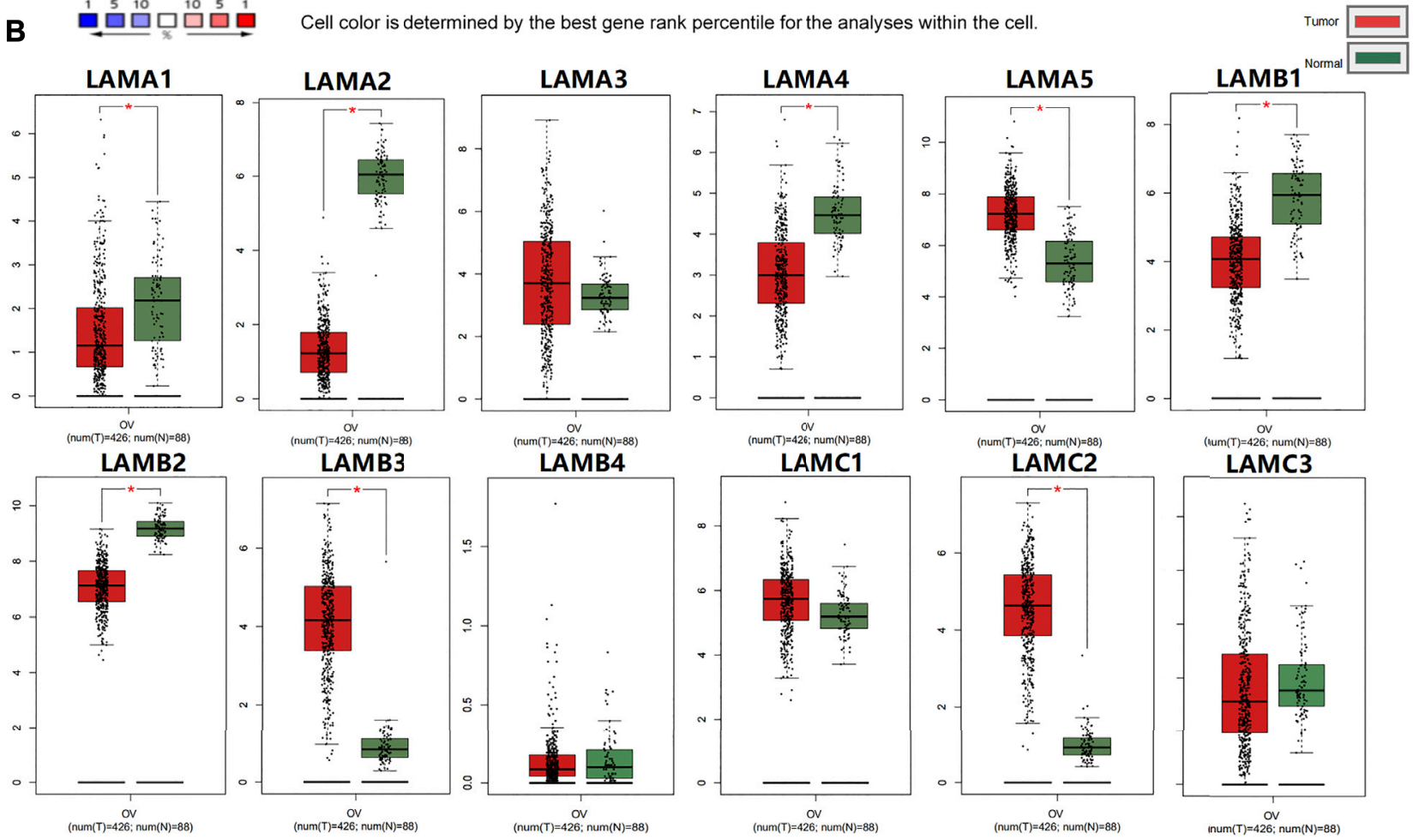

FIGURE 2 | Expression of laminin members in normal ovary and OC tissues. (A) Transcriptional expression of Laminins in OC (ONCOMINE database). (B) Laminin expression in OC (GEPIA2). ${ }^{*} p<0.05 ;{ }^{* *} p<0.01 ;{ }^{* \star *} p<0.001 ;{ }^{* * \star *} p<0.0001$. The red columns represented tumor tissues, and the green column represented normal tissues.

in the cBioPortal database. Figure 1A depicts high laminin mutation rates in the OC samples. Laminin gene expression levels were altered in 191 samples obtained from 303 ovarian cancer patients $(63 \%)$, and LAMA5 was observed to be the most frequently mutated gene (30\%). Other genes with high mutation rates were LAMC1(16\%), LAMC2 (12\%), LAMA3 (11\%) and LAMB1 (11\%). Laminin gene amplification and mRNA alteration occurred relatively more often in OC patients. The LAMB2 and LAMC1 mRNA expression levels were significantly and positively correlated with their relative linear copy number alteration (CNA) values. However, the LAMA1/A3/A5, LAMB3, and LAMC2 mRNA expression levels were only weakly correlated with their relative linear CNA values (Supplementary Figure S1). The foregoing results indicated that genetic changes in laminins were correlated with poor OS (Figure 1B, $p=0.0459$ ) and DFS (Figure 1C, $p=0.0227$ ) in OC patients. They also demonstrated that changes in laminin genes and copy numbers occurred in certain patients with $\mathrm{OC}$ and might be related to poor prognosis.

\section{Aberrant Laminin mRNA Expression in Ovarian Cancer}

The mRNA expression levels of 12 laminin members were evaluated for OC patients registered in the ONCOMINE database. ONCOMINE includes data on extensive independent studies conducted using various patient cohorts. Figure 2A shows that the mRNA expression levels of 12 laminin family members were detected using the ONCOMINE database and were compared against normal tissues. At least one dataset indicated that the expression levels of LAMA5 and LAMC2 mRNAs were significantly upregulated. In contrast, the expression levels of LAMA2/A4 and LAMB2 mRNAs were significantly downregulated. However, certain studies demonstrated that LAMA3, LAMB1/B3 and LAMC1 were highly expressed in OC whereas other reports presented the opposite findings (Supplementary Table S1).

We used GEPIA2 to evaluate laminin mRNA expression in OC and normal ovary tissues. The mRNA expression levels of LAMA5, LAMB3, and LAMC2 were higher, while those of 


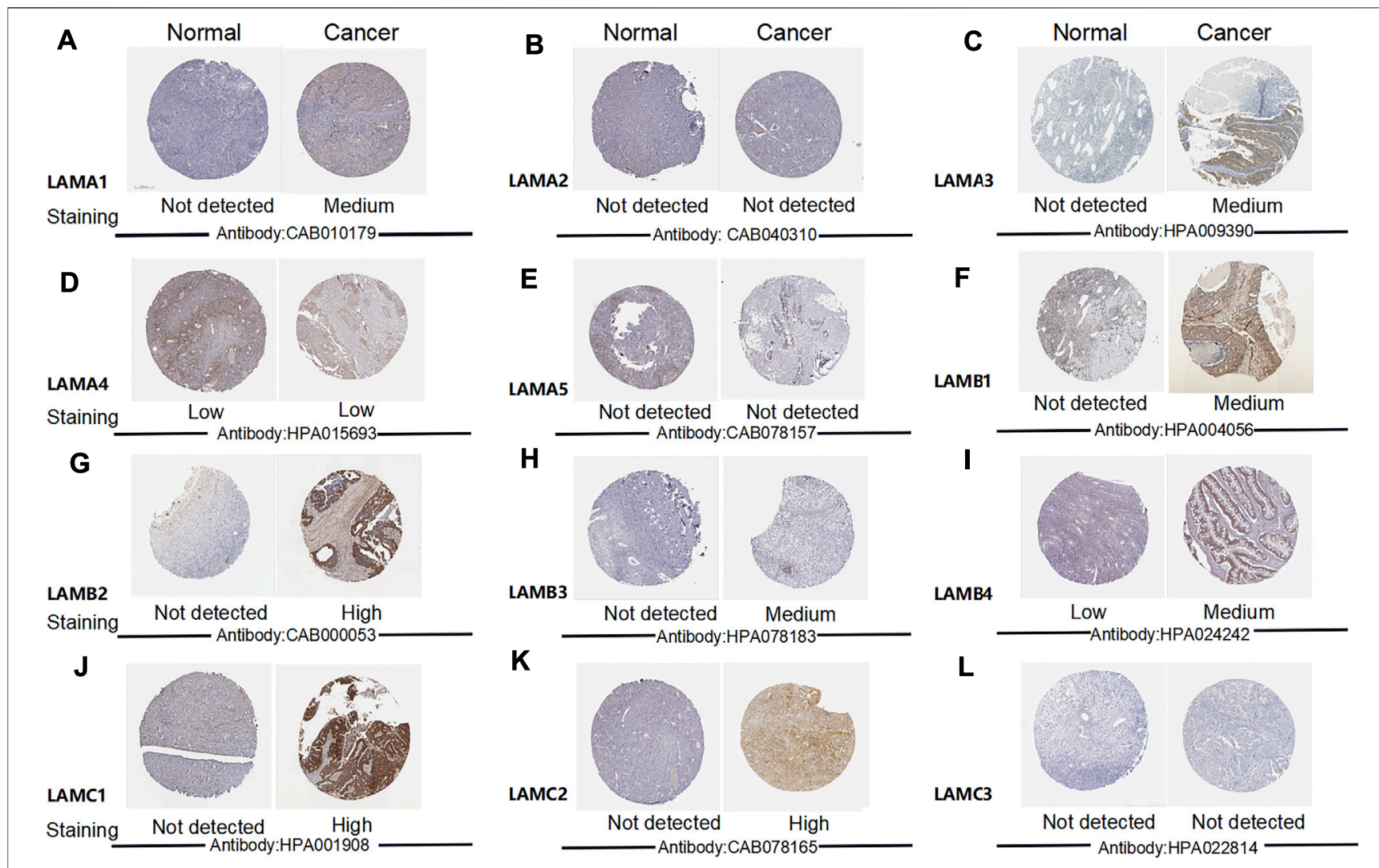

FIGURE 3 | Images depicting IHC analysis performed for distinct laminin family members in OC and normal ovary tissues (the Human Protein Atlas).

LAMA1/A2/A4 and LAMB1/B2 were lower in OC tissues than normal ovary tissues (Figure 2B). Our findings suggested that LAMA5, LAMB3, and LAMC2 were overexpressed, whereas the expression levels of LAMA2/A4 and LAMB1/B2 were downregulated in OC tissues.

\section{Expression of 12 Laminin Proteins in Ovarian Cancer Patients}

We used the Human Protein Atlas (HPA) to explore laminin protein expression patterns in OC (Figure 3). Images depicting the results of immunohistochemical (IHC) staining performed for 11 or 12 samples were used for comparison. This revealed the expression of LAMA1 (six positive, six negative), LAMA2 (zero positive, twelve negative), LAMA3 (eleven positive, one negative), LAMA4 (five positive, seven negative), LAMA5 (one positive, eleven negative), LAMB1 (seven positive, five negative), LAMB2 (seven positive, five negative), LAMB3 (twelve positive, zero negative), LAMB4 (nine positive, two negative), LAMC1 (nine positive, two negative), LAMC2 (twelve positive, zero negative), and LAMC3 (zero positive, 12 negative) laminin proteins. The number of LAMA1-positive and LAMA1-negative cases was similar for the OC samples, but LAMA1 was not expressed in normal ovary tissues. LAMA 3 and LAMB1/B3 proteins were expressed at medium or low levels in OC tissues but protein expression was not detected in normal ovary tissues. LAMB2 and LAMC1/C2 were expressed at high, moderate, or low levels in OC tissues but protein expression was not detected in normal ovary tissues. LAMB4 protein was expressed at medium or low levels in OC tissues, but their expression was not detected in normal ovary tissues. The LAMA4 protein expression levels were equally low in both $\mathrm{OC}$ and normal ovary tissues. LAMC2 proteins were expressed at high, moderate, or low levels in OC tissues but were not expressed in normal ovary tissues. However, no LAMA2 or LAMC3 protein expression was detected in OC or normal ovary tissues.

We also investigated the associations between laminin mRNA and protein expression. LAMA3 mRNA and protein expression were strongly correlated. There were moderate correlations between the mRNA and protein levels of LAMA1/A2/A4, LAMB1/B3, and LAMC2, LAMA5 and LAMC1 mRNA and protein expression levels were weakly correlated. There was no correlation between LAMB2 mRNA and LAMB2 protein expression, and no data were available for LAMB4 or LAMC3 mRNA and protein correlations (Supplementary Figure S2).

The preceding results suggested that the proteins expression levels of LAMA3, LAMB1/B2/B3, and LAMC1/C2 were higher in OC than normal tissues and there were varying degrees of correlation between the protein and mRNA expression levels of LAMA1/A2/A3/A4/A5, LAMB1/B3, and LAMC1/C2. 


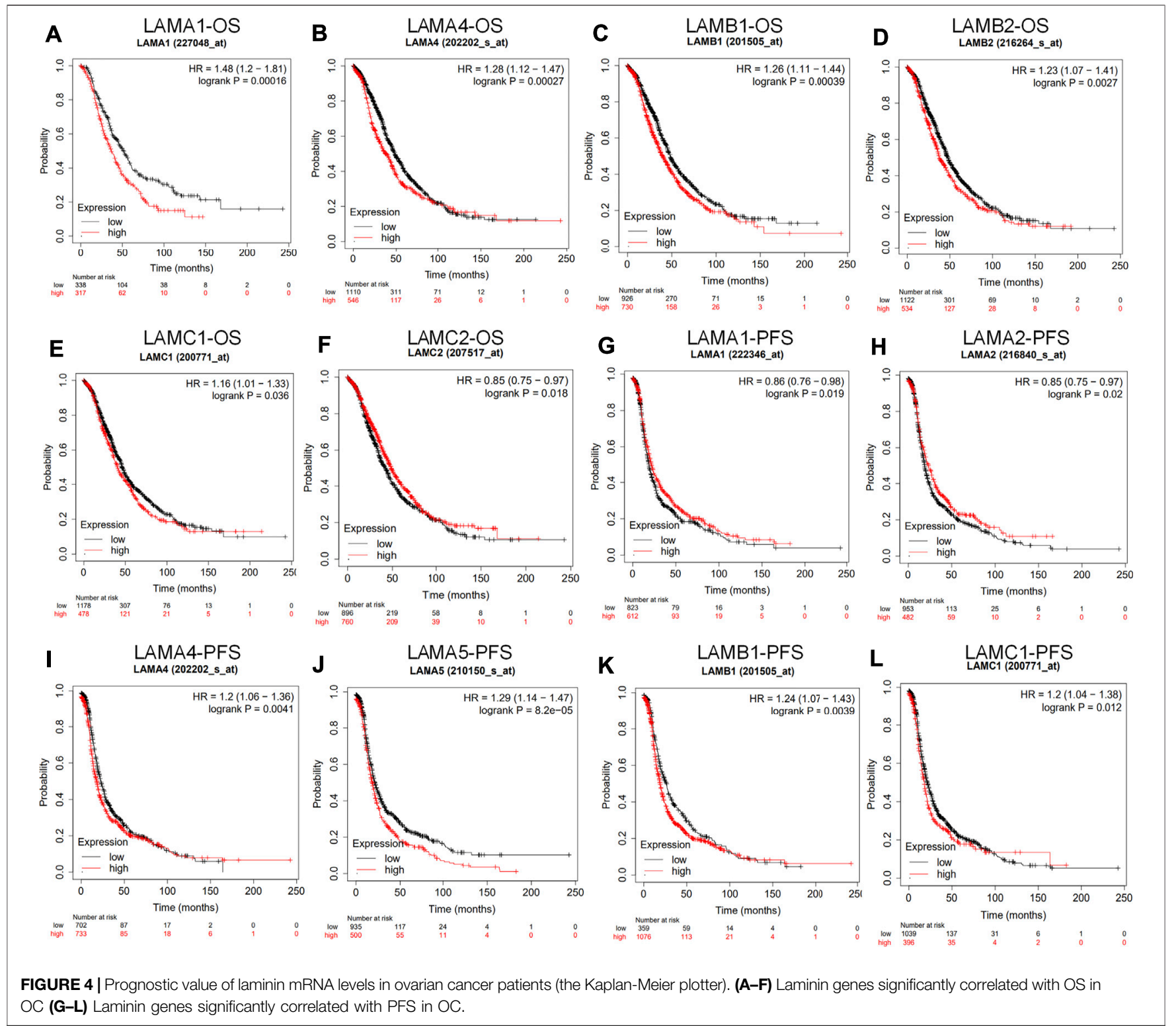

\section{Prognostic Value of Laminin Genes in Ovarian Cancer}

We used the Kaplan Meier plotter to investigate the impact of laminin mRNA level on survival in patients with OC. Upregulated expression levels of LAMA1/A4, LAMB1/B2, and LAMC1 and downregulated expression levels of LAMC2 were significantly and positively associated with poor OS in OC patients (Figures 4A-F). While upregulated expression levels of LAMA4/A5, LAMB1, and LAMC1 mRNAs were significantly and positively associated with poor PFS, elevated LAMA1/A2 expression levels were significantly and positively associated with better PFS (Figures 4G-L).

In general, the foregoing results showed that increases in LAMA4, LAMB1 and LAMC1 mRNA expression levels were positively related to poor OS and PFS, whereas upregulated
LAMA5 mRNA level was positively related to worse PFS. Thus, increased LAMC2 mRNA expression may be considered to predict longer OS and upregulated LAMA1/A2 mRNA level is associated with better PFS in patients with OC.

\section{Correlation of Laminin Gene Expression With Clinicopathological Features and Prognosis in Ovarian Cancer Patients}

We used the Kaplan Meier plotter to investigate the associations among laminin mRNA expression, OS, and PFS in patients at different clinical stages and pathological grades of OC. Table 1 shows that for patients with stage I or stage II OC, the LAMA1 and LAMB1 mRNA expression levels were strongly associated with worse OS (HR > 1), and the LAMA3 and LAMB4 mRNA 
TABLE 1 | The relationship between Laminins and OS in different tumor grades and stages of OC (Kaplan-Meier plotter). Bold font indicates significant difference.

\begin{tabular}{|c|c|c|c|c|c|c|c|c|c|c|}
\hline \multirow[t]{2}{*}{ Genes } & \multicolumn{2}{|c|}{ Stage I + II (179 cases) } & \multicolumn{2}{|c|}{ Stage III ( 1,079 cases) } & \multicolumn{2}{|c|}{ Stage IV (189 cases) } & \multicolumn{2}{|c|}{ Grade $1+2$ (381 cases) } & \multicolumn{2}{|c|}{ Grade 3 ( 1,024 cases) } \\
\hline & $\begin{array}{c}\text { HR } \\
(95 \% \mathrm{Cl})\end{array}$ & $p$-value & $\begin{array}{c}\text { HR } \\
(95 \% \mathrm{Cl})\end{array}$ & $p$-value & $\begin{array}{c}\text { HR } \\
(95 \% \mathrm{Cl})\end{array}$ & $p$-value & $\begin{array}{c}\text { HR } \\
(95 \% \mathrm{Cl})\end{array}$ & $p$-value & $\begin{array}{c}\text { HR } \\
(95 \% \mathrm{Cl})\end{array}$ & $p$-value \\
\hline LAMA1 & $\begin{array}{c}4.66 \\
(1.29-16.87)\end{array}$ & 0.01 & $\begin{array}{c}1.47 \\
(1.15-1.88)\end{array}$ & 0.0022 & $\begin{array}{c}2.15 \\
(1.16-3.98)\end{array}$ & 0.012 & $\begin{array}{c}1.99 \\
(1.25-3.19)\end{array}$ & 0.0034 & $\begin{array}{c}1.57 \\
(1.22-2.03)\end{array}$ & 0.00039 \\
\hline LAMA2 & $\begin{array}{c}0.3 \\
(0.09-1.02)\end{array}$ & 0.041 & $\begin{array}{c}1.19 \\
(0.98-1.43)\end{array}$ & 0.079 & $\begin{array}{c}1.25 \\
(0.87-1.81)\end{array}$ & 0.23 & $\begin{array}{c}0.75 \\
(0.52-1.07)\end{array}$ & 0.11 & $\begin{array}{c}1.13 \\
(0.95-1.35)\end{array}$ & 0.16 \\
\hline LAMA3 & $\begin{array}{c}0.33 \\
(0.15-0.72)\end{array}$ & 0.0034 & $\begin{array}{c}0.89 \\
(0.75-1.05)\end{array}$ & 0.17 & $\begin{array}{c}1.53 \\
(1.06-2.23)\end{array}$ & 0.023 & $\begin{array}{c}0.69 \\
(0.5-0.94)\end{array}$ & 0.018 & $\begin{array}{c}1.13 \\
(0.96-1.33)\end{array}$ & 0.15 \\
\hline LAMA4 & $\begin{array}{c}1.57 \\
(0.68-3.62)\end{array}$ & 0.28 & $\begin{array}{c}1.28 \\
(1.08-1.51)\end{array}$ & 0.0051 & $\begin{array}{c}0.84 \\
(0.58-1.21)\end{array}$ & 0.35 & $\begin{array}{c}1.44 \\
(1.08-1.92)\end{array}$ & 0.012 & $\begin{array}{c}1.23 \\
(1.03-1.47)\end{array}$ & 0.021 \\
\hline LAMA5 & $\begin{array}{c}1.96 \\
(0.89-4.29)\end{array}$ & 0.088 & $\begin{array}{c}0.85 \\
(0.72-1.01)\end{array}$ & 0.06 & $\begin{array}{c}1.72 \\
(1.18-2.51)\end{array}$ & 0.004 & $\begin{array}{c}1.2 \\
(0.9-1.61)\end{array}$ & 0.22 & $\begin{array}{c}1.25 \\
(1.06-1.49)\end{array}$ & 0.0082 \\
\hline LAMB1 & $\begin{array}{c}2.57 \\
(1.19-5.56)\end{array}$ & 0.013 & $\begin{array}{c}1.43 \\
(1.2-1.72)\end{array}$ & 8.7E-05 & $\begin{array}{c}0.75 \\
(0.51-1.11)\end{array}$ & 0.15 & $\begin{array}{c}1.47 \\
(1.1-1.96)\end{array}$ & 0.0083 & $\begin{array}{c}1.32 \\
(1.1-1.59)\end{array}$ & 0.0034 \\
\hline LAMB2 & $\begin{array}{c}1.77 \\
(0.71-4.41)\end{array}$ & 0.22 & $\begin{array}{c}1.14 \\
(0.96-1.35)\end{array}$ & 0.13 & $\begin{array}{c}1.16 \\
(0.8-1.69)\end{array}$ & 0.42 & $\begin{array}{c}1.28 \\
(0.93-1.76)\end{array}$ & 0.13 & $\begin{array}{c}0.88 \\
(0.73-1.05)\end{array}$ & 0.16 \\
\hline LAMB3 & $\begin{array}{c}0.46 \\
(0.19-1.1)\end{array}$ & 0.075 & $\begin{array}{c}1.2 \\
(1.01-1.44)\end{array}$ & 0.04 & $\begin{array}{c}0.64 \\
(0.44-0.92)\end{array}$ & 0.015 & $\begin{array}{c}0.81 \\
(0.59-1.11)\end{array}$ & 0.18 & $\begin{array}{c}1.14 \\
(0.95-1.37)\end{array}$ & 0.15 \\
\hline LAMB4 & $\begin{array}{c}0.34 \\
(0.16-0.74)\end{array}$ & 0.0045 & $\begin{array}{c}0.81 \\
(0.68-0.98)\end{array}$ & 0.027 & $\begin{array}{c}0.7 \\
(0.47-1.05)\end{array}$ & 0.08 & $\begin{array}{c}0.69 \\
(0.5-0.95)\end{array}$ & 0.024 & $\begin{array}{c}0.9 \\
(0.75-1.07)\end{array}$ & 0.23 \\
\hline LAMC1 & $\begin{array}{c}1.77 \\
(0.71-4.41)\end{array}$ & 0.22 & $\begin{array}{c}1.14 \\
(0.96-1.35)\end{array}$ & 0.13 & $\begin{array}{c}1.16 \\
(0.8-1.69)\end{array}$ & 0.42 & $\begin{array}{c}1.28 \\
(0.93-1.76)\end{array}$ & 0.13 & $\begin{array}{c}0.88 \\
(0.73-1.05)\end{array}$ & 0.16 \\
\hline LAMC2 & $\begin{array}{c}0.35 \\
(0.11-1.18)\end{array}$ & 0.078 & $\begin{array}{c}0.83 \\
(0.69-0.99)\end{array}$ & 0.041 & $\begin{array}{c}1.37 \\
(0.94-2.01)\end{array}$ & 0.1 & $\begin{array}{c}0.7 \\
(0.51-0.95)\end{array}$ & 0.02 & $\begin{array}{c}0.89 \\
(0.75-1.06)\end{array}$ & 0.19 \\
\hline LAMC3 & $\begin{array}{c}1.48 \\
(0.65-3.34)\end{array}$ & 0.34 & $\begin{array}{c}1.11 \\
(0.92-1.33)\end{array}$ & 0.28 & $\begin{array}{c}1.43 \\
(0.99-2.05)\end{array}$ & 0.055 & $\begin{array}{c}0.8 \\
(0.59-1.06)\end{array}$ & 0.12 & $\begin{array}{c}1.15 \\
(0.97-1.37)\end{array}$ & 0.11 \\
\hline
\end{tabular}

TABLE 2 | The relationship between laminins and PFS in different tumor grades and stages of OC (Kaplan-Meier plotter). Bold font indicates significant difference.

\begin{tabular}{|c|c|c|c|c|c|c|c|c|c|c|}
\hline \multirow[t]{2}{*}{ Genes } & \multicolumn{2}{|c|}{ Stage I + II (179 cases) } & \multicolumn{2}{|c|}{ Stage III ( 1,079 cases) } & \multicolumn{2}{|c|}{ Stage IV (189 cases) } & \multicolumn{2}{|c|}{ Grade $1+2$ (381 cases) } & \multicolumn{2}{|c|}{ Grade 3 (1,024 cases) } \\
\hline & $\begin{array}{c}\text { HR } \\
(95 \% \mathrm{Cl})\end{array}$ & $p$-value & $\begin{array}{c}\text { HR } \\
(95 \% \mathrm{Cl})\end{array}$ & $p$-value & $\begin{array}{c}\text { HR } \\
(95 \% \mathrm{Cl})\end{array}$ & $p$-value & $\begin{array}{c}\text { HR } \\
(95 \% \mathrm{Cl})\end{array}$ & $p$-value & $\begin{array}{c}\text { HR } \\
(95 \% \mathrm{Cl})\end{array}$ & $p$-value \\
\hline LAMA1 & $\begin{array}{c}1.97 \\
(0.93-4.15)\end{array}$ & 0.071 & $\begin{array}{c}1.18 \\
(0.94-1.47)\end{array}$ & 0.15 & $\begin{array}{c}0.79 \\
(0.47-1.34)\end{array}$ & 0.39 & $\begin{array}{c}0.86 \\
(0.6-1.22)\end{array}$ & 0.39 & $\begin{array}{c}0.89 \\
(0.68-1.16)\end{array}$ & 0.39 \\
\hline LAMA2 & $\begin{array}{c}0.26 \\
(0.12-0.58)\end{array}$ & 0.00042 & $\begin{array}{c}1.19 \\
(0.99-1.42)\end{array}$ & 0.059 & $\begin{array}{c}1.16 \\
(0.78-1.73)\end{array}$ & 0.46 & $\begin{array}{c}0.59 \\
(0.44-0.79)\end{array}$ & 0.00025 & $\begin{array}{c}1.16 \\
(0.96-1.41)\end{array}$ & 0.12 \\
\hline LAMA3 & $\begin{array}{c}0.39 \\
(0.22-0.69)\end{array}$ & 0.00074 & $\begin{array}{c}0.87 \\
(0.74-1.01)\end{array}$ & 0.067 & $\begin{array}{c}1.81 \\
(1.24-2.64)\end{array}$ & 0.0018 & $\begin{array}{c}0.67 \\
(0.5-0.89)\end{array}$ & 0.0051 & $\begin{array}{c}1.1 \\
(0.93-1.31)\end{array}$ & 0.26 \\
\hline LAMA4 & $\begin{array}{c}0.4 \\
(0.18-0.9)\end{array}$ & 0.022 & $\begin{array}{c}1.29 \\
(1.1-1.5)\end{array}$ & 0.0014 & $\begin{array}{c}0.76 \\
(0.5-1.15)\end{array}$ & 0.19 & $\begin{array}{c}1.73 \\
(1.3-2.3)\end{array}$ & 0.00014 & $\begin{array}{c}1.22 \\
(1.03-1.44)\end{array}$ & 0.021 \\
\hline LAMA5 & $\begin{array}{c}2.65 \\
(1.45-4.83)\end{array}$ & 0.00096 & $\begin{array}{c}1.31 \\
(1.12-1.54)\end{array}$ & 0.00097 & $\begin{array}{c}1.84 \\
(1.26-2.68)\end{array}$ & 0.0014 & $\begin{array}{c}1.44 \\
(1.07-1.93)\end{array}$ & 0.014 & $\begin{array}{c}1.42 \\
(1.19-1.7)\end{array}$ & 8.7E-05 \\
\hline LAMB1 & $\begin{array}{c}0.5 \\
(0.28-0.88)\end{array}$ & 0.015 & $\begin{array}{c}1.18 \\
(1.01-1.38)\end{array}$ & 0.033 & $\begin{array}{c}1.3 \\
(0.89-1.9)\end{array}$ & 0.18 & $\begin{array}{c}1.16 \\
(0.87-1.54)\end{array}$ & 0.31 & $\begin{array}{c}1.1 \\
(0.93-1.3)\end{array}$ & 0.26 \\
\hline LAMB2 & $\begin{array}{c}0.73 \\
(0.41-1.31)\end{array}$ & 0.29 & $\begin{array}{c}1.22 \\
(1.03-1.44)\end{array}$ & 0.022 & $\begin{array}{c}1.31 \\
(0.91-1.9)\end{array}$ & 0.15 & $\begin{array}{c}1.16 \\
(0.85-1.58)\end{array}$ & 0.35 & $\begin{array}{c}1.25 \\
(1.04-1.49)\end{array}$ & 0.017 \\
\hline LAMB3 & $\begin{array}{c}0.55 \\
(0.28-1.08)\end{array}$ & 0.08 & $\begin{array}{c}1.09 \\
(0.92-1.3)\end{array}$ & 0.32 & $\begin{array}{c}1.53 \\
(0.99-2.35)\end{array}$ & 0.053 & $\begin{array}{c}0.74 \\
(0.53-1.04)\end{array}$ & 0.079 & $\begin{array}{c}1.1 \\
(0.91-1.32)\end{array}$ & 0.33 \\
\hline LAMB4 & $\begin{array}{c}0.72 \\
(0.41-1.27)\end{array}$ & 0.25 & $\begin{array}{c}1.13 \\
(0.94-1.34)\end{array}$ & 0.19 & $\begin{array}{c}0.76 \\
(0.51-1.13)\end{array}$ & 0.18 & $\begin{array}{c}0.84 \\
(0.63-1.12)\end{array}$ & 0.22 & $\begin{array}{c}1.08 \\
(0.9-1.28)\end{array}$ & 0.42 \\
\hline LAMC1 & $\begin{array}{c}0.73 \\
(0.41-1.31)\end{array}$ & 0.29 & $\begin{array}{c}1.22 \\
(1.03-1.44)\end{array}$ & 0.022 & $\begin{array}{c}1.31 \\
(0.91-1.9)\end{array}$ & 0.15 & $\begin{array}{c}1.16 \\
(0.85-1.58)\end{array}$ & 0.35 & $\begin{array}{c}1.25 \\
(1.04-1.49)\end{array}$ & 0.017 \\
\hline LAMC2 & $\begin{array}{c}0.42 \\
(0.21-0.84)\end{array}$ & 0.012 & $\begin{array}{c}1.09 \\
(0.91-1.29)\end{array}$ & 0.36 & $\begin{array}{c}1.22 \\
(0.81-1.85)\end{array}$ & 0.33 & $\begin{array}{c}0.64 \\
(0.48-0.86)\end{array}$ & 0.0031 & $\begin{array}{c}1.24 \\
(1.02-1.52)\end{array}$ & 0.034 \\
\hline LAMC3 & $\begin{array}{c}0.7 \\
(0.39-1.24)\end{array}$ & 0.22 & $\begin{array}{c}1.18 \\
(1.01-1.38)\end{array}$ & 0.033 & $\begin{array}{c}1.34 \\
(0.89-2.02)\end{array}$ & 0.16 & $\begin{array}{c}0.85 \\
(0.63-1.14)\end{array}$ & 0.27 & $\begin{array}{c}1.27 \\
(1.07-1.52)\end{array}$ & 0.0077 \\
\hline
\end{tabular}


expression levels were significantly related to better OS $(\mathrm{HR}<1)$. For stage III OC patients, the LAMA1/A4, LAMB1, and LAMB3 mRNA expression levels were markedly associated with unfavorable OS, while the LAMB4 and LAMC2 mRNA expression levels were strongly related to favorable OS. For stage IV OC patients, transcriptional LAMB3 expression was significantly associated with longer OS, while transcriptional LAMA1/A3/A5 expression were significantly correlated with shorter OS. The data showed that for patients with grade 1 or 2 OC, the LAMA3, LAMB4 and LAMC2 mRNA expression levels were significantly correlated with longer OS; however, the LAMA1/A4 and LAMB1 mRNA expression levels were significantly related to shorter OS. For grade 3 OC patients, the LAMA1/A4/A5 and LAMB1 mRNA expression levels were significantly associated with poor OS.

Table 2 shows that the LAMA2/A3/A4, LAMB1 and LAMC2 mRNA expression levels were significantly associated with longer PFS in stage I or stage II OC patients, while the LAMA5 mRNA expression levels was significantly related to shorter PFS in the same patients. In stage III OC patients, the LAMA4/A5, LAMB1/ $\mathrm{B} 2$, and LAMC1/C3 mRNA expression levels were significantly related to poor PFS. The LAMA3 and LAMA5 mRNA expression level were significantly correlated with unfavorable PFS in stage IV OC patients. The LAMA2/A3 and LAMC2 mRNA expression levels were markedly correlated with longer PFS in grades 1 and 2 OC patients, whereas the LAMA4 and LAMA5 mRNA expression levels were significantly associated with shorter PFS in grades 1,2, and 3 OC patients. The LAMB2 and LAMC1/C2/ C3 mRNA expression levels were markedly correlated with worse PFS in grade 3 OC patients.

Based on the OS and PFS results shown in Tables 1 and 2, upregulated expression levels of LAMA1/A4/A5 and LAMB1 may indicate poor prognosis in OC patients and LAMA5 might be considered the main negative prognostic factor for all stages and grades of OC. These results also suggest that LAMC2 expression may be used to predict a relatively longer prognosis for patients with OC.

\section{Diagnostic Evaluation of Laminins in Ovarian Cancer}

We explored clinical data and information on laminin mRNA expression for OC patients in TCGA and extracted data from GTEx for the corresponding normal tissues. Data on 515 cases were available and the dataset was used to investigate the relationships of specific laminins via ROC (receiver operating characteristic) curve regression analysis. Our results were evaluated based on ROC curve AUC $>0.70$. We found that LAMA2 (AUC: 1.000; 95\% CI: 0.999-1.000), LAMA4 (AUC: 0.881; 95\% CI: 0.851-0.912), LAMA5 (AUC: 0.894; 95\% CI: 0.859-0.928), LAMB1 (AUC: 0.889; 95\% CI: 0.854-0.924), LAMB2 (AUC: 0.994; 95\% CI: 0.990-0.999), LAMB3 (AUC: 0.977; 95\% CI: 0.955-0.999), and LAMC2 (AUC: 0.992; 95\% CI: 0.985-0.999) were qualified (Supplementary Figure S3).

Overall, the ROC analysis of the laminins in the OC sets indicated that LAMA2/A4/A5, LAMB1/B2/B3, and LAMC2 could be considered to accurately differentiate between tumor and non-tumor tissues.

\section{Association Between Laminin Expression and Immune Cell Infiltration in Ovarian Cancer}

Epithelial ovarian cancer (EOC) is susceptible to immune recognition[26]. CD8+TIL expression is associated with better prognosis in advanced EOC patients[27]. Based on the existing literature, we used the online TIMER database to explore associations between laminins and immune infiltration levels in OC patients. There were negative correlations between OC tumor purity and LAMA4 and LAMB1. The correlation ratio was the most considerable for LAMA4 $(\mathrm{r}=-0.526 ; p=8.23 \mathrm{E}-36)$. LAMA4 was positively weakly correlated with macrophage $(\mathrm{r}=0.19 ; p=2.89 \mathrm{E}-05)$, neutrophil $(\mathrm{r}=0.142 ; p=1.87 \mathrm{E}-03)$ and dendritic cell $(\mathrm{r}=$ $0.171 ; p=1.64 \mathrm{E}-04)$, while LAMB1 was positively weakly correlated with only macrophage $(\mathrm{r}=0.17 ; p=1.76 \mathrm{E}-04)$. Details of the relationships between immune cell types and laminin members are illustrated in Figure $\mathbf{5}$ and Supplementary Figure S4.

LAMA1 was negatively correlated with CD8+ T cell $(\mathrm{r}=$ $-0.692 ; p=6.37 \mathrm{E}-11)$, $\mathrm{B}$ cell $(\mathrm{r}=-0.303 ; p=1.21 \mathrm{E}-11)$, neutrophil $(\mathrm{r}=-0.317 ; p=1.10 \mathrm{E}-12)$ and dendritic cell $(\mathrm{r}=$ $-0.32 ; p=6.95 \mathrm{E}-13)$. LAMA5 was significantly and negatively correlated with macrophage $(\mathrm{r}=-0.207 ; p=4.84 \mathrm{E}-06)$, neutrophil $(\mathrm{r}=-0.24 ; p=1.01 \mathrm{E}-7)$ and dendritic cell $(\mathrm{r}=$ $-0.249 ; p=3.08 \mathrm{E}-08)$. LAMC1 was significantly and negatively correlated with CD8 $+\mathrm{T}$ cell $(\mathrm{r}=-0.233 ; p=2.53 \mathrm{E}$ 07). However, LAMA2/A3, LAMB2/B3/B4, and LAMC2/C3 were not associated with any specific immune cell types (Supplementary Figure S4).

\section{Relationship Between Laminin Genes and Ovarian Cancer Metastasis}

The development of platinum resistance in tumors leads to inferior outcomes and remains an obstacle in efficacious anticancer therapy. To investigate whether laminin genes could be implicated in the development of endogenous chemotherapy resistance, we retrieved data from GEO regarding the responses of OC patients to chemotherapy. GSE131978 defined patients with tumor progression times $>12$ months as being relatively platinum-sensitive and those with tumor progression times < six months as being platinum-resistant. LAMA1 and LAMB3 expression levels were upregulated in platinum-resistant OC patients (Supplementary Table S2). We also explored the GSE58470 dataset[28]. It includes the parental cisplatin-sensitive IGROV-1 and the platinum-resistant variant IGROV-1/Pt1 OC cell lines. LAMC2 expression was significantly upregulated in the platinum-resistant mutants (Supplementary Table S2). Hence, LAMA1, LAMB3, and LAMC2 may play important roles in the development of platinum resistance. 


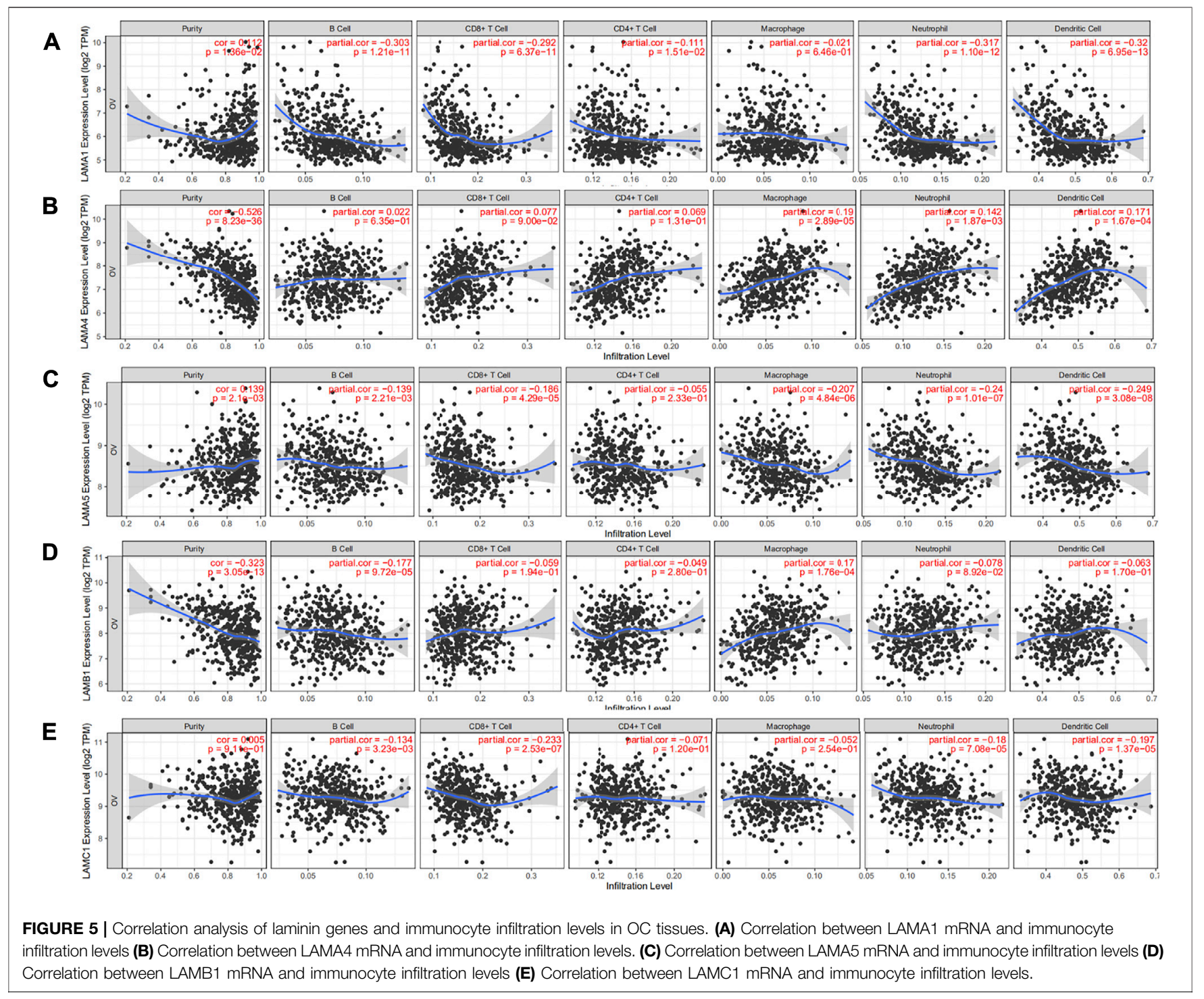

\section{Kyoto Encyclopedia of Genes and Genomes Pathway, Gene Ontology Term, and Interaction Network Analyses of Laminin Family Genes}

In the gene interaction network generated based on the use of GeneMANIA[29], we observed that laminin family genes might be associated with ITG and netrin family genes (Figure 6A). We used STRING[25] to analyze the protein-protein interaction network (local clustering coefficient $=0.875$ ). Laminin proteins were co-expressed with ITG, nidogen, dystrophin, dystroglycan, collagen types XVII and VII, and alpha 1 chain proteins (Figure 6B).

The GO and KEGG databases revealed laminin functions and the genes that were significantly associated with their alterations. Biological processes such as GO:0030198 (extracellular matrix organization), GO:0001568 (blood vessel development), and others were remarkably influenced by laminin mutations in OC (Supplementary Figure S5A). Molecular functions such as GO:0004060 (arylamine $\mathrm{N}$-acetyltransferase activity), GO:0001228 (DNA-binding transcription activator activity, RNA polymerase II-specific), GO:0005201 (extracellular matrix structural constituent), GO: 0005509 (calcium ion binding), GO:0005518 (collagen binding), GO:0050839 (cell adhesion molecule binding), and others were significantly associated with laminin alterations (Supplementary Figure S5B). Laminin mutations also significantly affected cellular components including GO: 0031012 (extracellular matrix), GO:0070161 (anchoring junction), and GO:0005938 (cell cortex) (Supplementary Figure S5C). In the KEGG analysis, ten pathways including ko04512 (ECM-receptor interaction), ko04010 (MAPK signaling pathway), ko05412 (arrhythmogenic right ventricular cardiomyopathy (ARVC)), ko04210 (apoptosis), and others were affected by laminin mutations in OC (Supplementary Figure S5D). 


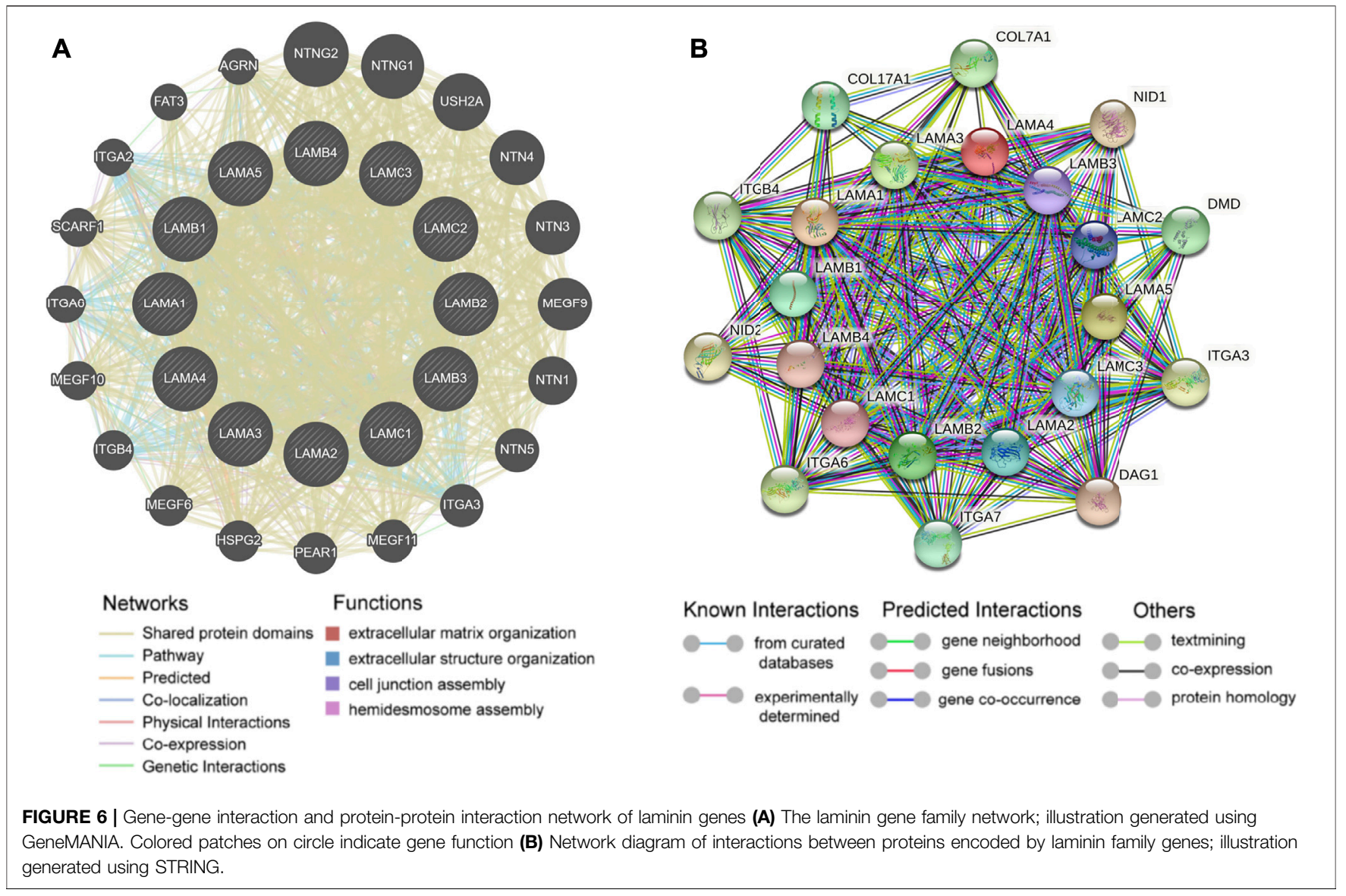

\section{DISCUSSION}

Our study demonstrated that certain OC patients presented with laminin mutations. The mutation frequencies were as follows: LAMA5, 30\%; LAMC1, 16\%; LAMC2, 12\%; LAMA3, 11\%; and LAMB1, 11\%. Laminin mutation was associated with poor prognosis in ovarian cancer. The LAMA5, LAMB3, and LAMC2 mRNA expression levels were higher in OC than those in normal ovary tissues and LAMA2/A4 and LAMB1 were downregulated in OC tissues, while the LAMA3, $\mathrm{LAMB} 1 / \mathrm{B} 2 / \mathrm{B} 3$, and $\mathrm{LAMC} 1 / \mathrm{C} 2$ protein expression levels were higher in OC than those in normal ovary tissues. A survival analysis demonstrated that upregulated levels of LAMA4, LAMB1, and LAMC1 mRNAs were positively associated with poor OS and PFS in OC patients. In OC, LAMA5 overexpression was related to poor prognosis in advanced OS, high-grade OS, and PFS at all stages and grades. However, elevated LAMA2 and LAMC2 mRNA expression levels were associated with better PFS in early-stage OC patients. LAMB3 and LAMC2 expression was significantly related to platinum resistance development in OC patients. The ROC analysis of the laminins in OC datasets showed that the LAMA2/A4/A5, LAMB1/B2/B3, and LAMC2 mRNA levels could be considered to effectively differentiate between malignant tumor and non-tumor tissues. LAMA4/A5, LAMB1, and LAMC1 may perform multiple functions in immunocyte infiltration in OC. LAMA4 and LAMB1 may be implicated in tumor purity.

In the present study, we found that LAMA5 might be crucial to OC occurrence and progression. Compared with normal ovary tissues, LAMA5 was the most frequently altered gene (30\%) and was overexpressed at mRNA level in OC patients. Moreover, LAMA5 was associated with poor PFS in all stages and grades and poor OS in stage IV and grade 3 OC. Bartolini et al. reported that LAMA5 was a molecular target in colorectal cancer cells with the KRAS mutation. Furthermore,the tumor microenvironment (TME) was overexpressed[9]. Gordon-Weeks et al. have reported that LAMA5 is necessary for liver metastasis as it promotes branch angiogenesis and modulates Notch signaling [12]. Maltseva D et al. demonstrated that LAMA5 knockdown led to Wnt- and mTORC1-dependent partial dedifferentiation of colorectal carcinoma which, in turn, was related to the activation of endoplasmic reticulum stress (ERS) signaling pathways promoting 5-fluorouracil (5-FU) sensitivity. Thus, LAMA5 is deemed a potential therapeutic antitumor target[30]. A recent study has shown that LAMA5 binds integrin-6 and promotes epithelial-to-mesenchymal transition (EMT). This research also identified LAMA5 as a putative antitumor target[30]. Nevertheless, the mechanism by which LAMA5 promotes OC has not been elucidated and merits further investigation in vivo and in vitro. 
We also identified other laminin family members involved in OC progression. The mutation frequency of LAMC1 was 16\% and it ranked second only to LAMA5. The LAMC1 mRNA and protein expressions levels were increased in OC compared to those in normal ovary tissue and indicated a worse prognosis for OC patients. RNA sequencing was performed to compare the transcriptomes between high-grade serous carcinomas (HGSC) and normal fallopian tube epithelia (FTE). Findings revealed that LAMC1 expression upregulation was associated with HGSC[31]. Kunitomi et al. stated that LAMC1 overexpression could be considered an effective biomarker in endometrial cancer patients requiring aggressive adjuvant therapy[32]. According to Zhang et al., LAMC1 overexpression indicates poor prognosis in hepatocellular carcinoma (HCC)[33]. LAMC1 overexpression also indicated poor prognosis for cutaneous squamous cell carcinoma[34] and prostate cancer[35]. LAMC1 may participate in HCC progression by regulating PKM2 expression via the PTEN/AKT pathway[6]. Nevertheless, the pathways affected by LAMC1 in ovarian cancer remain to be determined.

Our study speculated that the role of LAMC2 in the progression of OC remains to be validated. The mutation frequency of LAMC2 is $12 \%$ in OC and LAMC2 expression is upregulated in OC tissues. LAMC2 expression was upregulated in SKOV-3 (ovarian serous carcinoma cell line) compared with MCV152 (benign ovarian epithelial tumor line)[36]. LAMC2 expression upregulation was also confirmed in OC tissues and cells. It promoted OC cell proliferation and inhibited $\mathrm{OC}$ cell its apoptosis via the miR-125a-5p/LAMC2/p38 pathway[37]. Moreover, LAMC2 expression upregulation lowered the sensitivity of OC cells to the chemotherapeutic agents docetaxel and taxane via the PI3K/Akt axis[38]. LAMC2 expression upregulation was usually associated with worse prognosis for patients with head and neck squamous cell carcinoma (HNSC) [39], colorectal cancer[40], lung adenocarcinoma[41] and bladder cancer[42]. However, our bioinformatics analysis in the Kaplan-Meier plotter showed that OC patients with upregulated LAMC2 expression levels had better PFS and OS than those with low LAMC2 expression levels. The underlying explanation for this discrepancy must be clarified through large-scale clinical studies.

Our bioinformatics analysis suggested that several other laminin family members were associated with OC progression. LAMA1 overexpression was significantly associated with poor prognosis and platinum resistance development in OS. The LAMA2 and LAMA4 mRNA expression levels were relatively lower in OC tissues. However, a survival analysis showed that PFS worsened with increasing LAMA4 expression levels in OC patients. ROC analysis revealed that LAMA2/A4/A5, LAMB1/ $\mathrm{B} 2 / \mathrm{B} 3$, and LAMC2 could be considered to effectively distinguish OC patients from healthy subjects. The foregoing findings may provide new insights into targets for antitumor therapy and early diagnosis in OC.

Immunotherapy is a novel frontier in the treatment of recurrent EOC[27]. Approximately half of all advanced EOC patients presented with spontaneous antitumor response evidenced by the generation of tumor-specific lymphocytes and antibodies[26]. Our analysis speculated that LAMA1/A4/ A5, LAMB1, and LAMC1 were associated with the immune infiltration levels of OC. Li et al. found that LAMA5 in murine lymph node stromal cells (LNSCs) modulated the LN immune response by changing LN structure and T cell behavior[43]. LAMA4 and LAMA5 demonstrated complex formation necessary for regulating human and mouse CD4 T cells[44]. In mice, LAMA4 expression downregulation weakened the immune cells penetrating vessel walls[45]. In head and neck squamous cell carcinoma, LAMC2 expression was strongly associated with $\mathrm{B}$ cell, $\mathrm{CD} 8+\mathrm{T}$ cell, $\mathrm{CD} 4{ }^{+} \mathrm{T}$ cell, and macrophage infiltration levels[39]. The preceding discoveries may provide clues for immunotherapy in OC patients.

The present study had certain limitations. First, it depended on data retrieved from continuously monitored and expanded online databases. Hence, these changes could have influenced the results of this study. Studies with large sample sizes are warranted to validate our findings and to assess the feasibility of clinical laminin application as an OC treatment. Second, we did not investigate the indirect or direct mechanisms of different laminin proteins in OC. Future studies should be conducted to explore the specific modes of action of the different laminin members in OC. We plan to further study the role of laminins in $\mathrm{OC}$ in vitro in OC cell lines in terms of basic phenotypes such as cell cycle, apoptosis, and senescence and in vivo by constructing OC animal models.

The results of this research suggested that LAMA5 and LAMC1 might be considered important OC oncogenes and prognostic factors in OC. The present study also indicated that LAMA1/A4/A5, LAMB4, and LAMC1 might play important roles in the $\mathrm{OC}$ immune response and could be used to improve immunotherapy efficacy in OC. It is hoped that our findings will help improve treatment efficacy and prognostic accuracy in OC.

\section{DATA AVAILABILITY STATEMENT}

The original contributions presented in the study are included in the article/Supplementary Material, further inquiries can be directed to the corresponding author.

\section{AUTHOR CONTRIBUTIONS}

PY was involved in the concept and design of the study. DB drafted the manuscript. All authors read and approved the final manuscript.

\section{FUNDING}

This work is supported by the National Natural Science Foundation of China, Grant Nos. 82072893. 


\section{CONFLICT OF INTEREST}

The authors declare that the research was conducted in the absence of any commercial or financial relationships that could be construed as a potential conflict of interest.

\section{REFERENCES}

1. Bray F, Ferlay J, Soerjomataram I, Siegel RL, Torre LA, and Jemal A. Global Cancer Statistics 2018: GLOBOCAN Estimates of Incidence and Mortality Worldwide for 36 Cancers in 185 Countries. CA: A Cancer J Clinicians (2018) 68(6):394-424. doi:10.3322/caac.21492

2. Wu A, Zhang S, Liu J, Huang Y, Deng W, Shu G, et al. Integrated Analysis of Prognostic and Immune Associated Integrin Family in Ovarian Cancer. Front Genet (2020) 11:705. doi:10.3389/fgene.2020.00705

3. Torre LA, Trabert B, DeSantis CE, Miller KD, Samimi G, Runowicz CD, et al. Ovarian Cancer Statistics. CA: A Cancer J Clinicians (2018) 68(4):284-96. doi:10.3322/caac. 21456

4. Krzystyniak J, Ceppi L, Dizon DS, and Birrer MJ. Epithelial Ovarian Cancer: the Molecular Genetics of Epithelial Ovarian Cancer. Ann Oncol (2016) 27: i4-i10. doi:10.1093/annonc/mdw083

5. Bizama C, Benavente F, Salvatierra E, Gutiérrez-Moraga A, Espinoza JA, Fernández EA, et al. The Low-Abundance Transcriptome Reveals Novel Biomarkers, Specific Intracellular Pathways and Targetable Genes Associated With Advanced Gastric Cancer. Int J Cancer (2014) 134(4): 755-64. doi:10.1002/ijc.28405

6. Ye G, Qin Y, Wang S, Pan D, Xu S, Wu C, et al. Lamc1 Promotes the Warburg Effect in Hepatocellular Carcinoma Cells by Regulating PKM2 Expression through AKT Pathway. Cancer Biol Ther (2019) 20(5):711-9. doi:10.1080/ 15384047.2018.1564558

7. Wragg JW, Finnity JP, Anderson JA, Ferguson HJM, Porfiri E, Bhatt RI, et al. MCAM and LAMA4 Are Highly Enriched in Tumor Blood Vessels of Renal Cell Carcinoma and Predict Patient Outcome. Cancer Res (2016) 76(8): 2314-26. doi:10.1158/0008-5472.can-15-1364

8. Shkurnikov M, Nikulin S, Nersisyan S, Poloznikov A, Zaidi S, Baranova A, et al. LAMA4-Regulating miR-4274 and its Host Gene SORCS2 Play a Role in IGFBP6-dependent Effects on Phenotype of Basal-Like Breast Cancer. Front Mol Biosci (2019) 6:122. doi:10.3389/fmolb.2019.00122

9. Bartolini A, Cardaci S, Lamba S, Oddo D, Marchiò C, Cassoni P, et al. BCAM and LAMA5 Mediate the Recognition Between Tumor Cells and the Endothelium in the Metastatic Spreading of KRAS-Mutant Colorectal Cancer. Clin Cancer Res (2016) 22(19):4923-33. doi:10.1158/1078-0432.ccr15-2664

10. Sathyanarayana UG, Toyooka S, Padar A, Takahashi T, Brambilla E, Minna JD, et al. Epigenetic Inactivation of Laminin-5-Encoding Genes in Lung Cancers. Clin Cancer Res (2003) 9(7):2665-72. doi:10.1158/0008-5472.can-03-0701

11. Fujita M, Khazenzon NM, Bose S, Sekiguchi K, Sasaki T, Carter WG, et al. Overexpression of $\beta 1$-Chain-Containing Laminins in Capillary Basement Membranes of Human Breast Cancer and its Metastases. Breast Cancer Res (2005) 7(4):R411-21. doi:10.1186/bcr1011

12. Gordon-Weeks A, Lim SY, Yuzhalin A, Lucotti S, Vermeer JAF, Jones K, et al. Tumour-Derived Laminin a5 (LAMA5) Promotes Colorectal Liver Metastasis Growth, Branching Angiogenesis and Notch Pathway Inhibition. Cancers (Basel) (2019) 11(5):630. doi:10.3390/cancers11050630

13. Tzu J, Marinkovich MP, and biology c. Bridging Structure With Function: Structural, Regulatory, and Developmental Role of Laminins. Int J Biochem Cel Biol (2008) 40(2):199-214. doi:10.1016/j.biocel.2007.07.015

14. Hao J, Tuck AR, Prakash CR, Damdimopoulos A, Sjödin MOD, Lindberg J, et al. Culture of Human Ovarian Tissue in Xeno-Free Conditions Using Laminin Components of the Human Ovarian Extracellular Matrix. $J$ Assist Reprod Genet (2020) 37(9):2137-50. doi:10.1007/s10815-020-01886-4

15. Gao J, Aksoy BA, Dogrusoz U, Dresdner G, Gross B, Sumer SO, et al. Integrative Analysis of Complex Cancer Genomics and Clinical Profiles Using the cBioPortal. Sci Signaling (2013) 6(269):pl1. doi:10.1126/ scisignal. 2004088

\section{SUPPLEMENTARY MATERIAL}

The Supplementary Material for this article can be found online at: https://www.por-journal.com/articles/10.3389/pore.2021.1609855/ full\#supplementary-material

16. Rhodes DR, Yu J, Shanker K, Deshpande N, Varambally R, Ghosh D, et al ONCOMINE: a Cancer Microarray Database and Integrated Data-Mining Platform. Neoplasia (2004) 6(1):1-6. doi:10.1016/s1476-5586(04)80047-2

17. Tang Z, Kang B, Li C, Chen T, and Zhang Z. GEPIA2: an Enhanced Web Server for Large-Scale Expression Profiling and Interactive Analysis. Nucleic Acids Res (2019) 47(W1):W556-W560. doi:10.1093/nar/gkz430

18. Uhlén M, Fagerberg L, Hallström BM, Lindskog C, Oksvold P, Mardinoglu A, et al. Proteomics. Tissue-Based Map of the Human Proteome. Science (2015) 347(6220):1260419. doi:10.1126/science.1260419

19. Gyorffy B, Lánczky A, and Szállási Z. Implementing an Online Tool for Genome-Wide Validation of Survival-Associated Biomarkers in OvarianCancer Using Microarray Data from 1287 Patients. Endocr Relat Cancer (2012) 19(2):197-208. doi:10.1530/ERC-11-0329

20. Li T, Fan J, Wang B, Traugh N, Chen Q, Liu JS, et al. TIMER: A Web Server for Comprehensive Analysis of Tumor-Infiltrating Immune Cells. Cancer Res (2017) 77(21):e108-e110. doi:10.1158/0008-5472.can-17-0307

21. Barrett T, Troup DB, Wilhite SE, Ledoux P, Rudnev D, Evangelista C, et al. NCBI GEO: Archive for High-Throughput Functional Genomic Data. Nucleic Acids Res (2009) 37:D885-D890. doi:10.1093/nar/gkn764

22. Tassi RA, Gambino A, Ardighieri L, Bignotti E, Todeschini P, Romani C, et al. FXYD5 (Dysadherin) Upregulation Predicts Shorter Survival and Reveals Platinum Resistance in High-Grade Serous Ovarian Cancer Patients. $\mathrm{Br}$ J Cancer (2019) 121(7):584-92. doi:10.1038/s41416-019-0553-z

23. Meyniel J-P, Cottu PH, Decraene C, Stern M-H, Couturier J, Lebigot I, et al. A Genomic and Transcriptomic Approach for a Differential Diagnosis Between Primary and Secondary Ovarian Carcinomas in Patients With a Previous History of Breast Cancer. BMC Cancer (2010) 10:222. doi:10.1186/1471-2407$10-222$

24. Zhou Y, Zhou B, Pache L, Chang M, Khodabakhshi AH, Tanaseichuk O, et al. Metascape Provides a Biologist-Oriented Resource for the Analysis of SystemsLevel Datasets. Nat Commun (2019) 10(1):1523. doi:10.1038/s41467-01909234-6

25. Szklarczyk D, Morris JH, Cook H, Kuhn M, Wyder S, Simonovic M, et al. The STRING Database in 2017: Quality-Controlled Protein-Protein Association Networks, Made Broadly Accessible. Nucleic Acids Res (2017) 45:D362-D368. doi:10.1093/nar/gkw937

26. Bobisse S, Genolet R, Roberti A, Tanyi JL, Racle J, Stevenson BJ, et al. Sensitive and Frequent Identification of High Avidity Neo-Epitope Specific CD8 + T Cells in Immunotherapy-Naive Ovarian Cancer. Nat Commun (2018) 9(1): 1092. doi:10.1038/s41467-018-03301-0

27. Santoiemma PP, Reyes C, Wang L-P, McLane MW, Feldman MD, Tanyi JL, et al. Systematic Evaluation of Multiple Immune Markers Reveals Prognostic Factors in Ovarian Cancer. Gynecol Oncol (2016) 143(1):120-7. doi:10.1016/ j.ygyno.2016.07.105

28. Arrighetti N, Cossa G, De Cecco L, Stucchi S, Carenini N, Corna E, et al. PKCAlpha Modulation by miR-483-3p in Platinum-Resistant Ovarian Carcinoma Cells. Toxicol Appl Pharmacol (2016) 310:9-19. doi:10.1016/ j.taap.2016.08.005

29. Warde-Farley D, Donaldson SL, Comes O, Zuberi K, Badrawi R, Chao P, et al. The GeneMANIA Prediction Server: Biological Network Integration for Gene Prioritization and Predicting Gene Function. Nucleic Acids Res (2010) 38: W214-W220. doi:10.1093/nar/gkq537

30. Maltseva D, Raygorodskaya M, Knyazev E, Zgoda V, Tikhonova O, Zaidi S, et al. Knockdown of the a5 Laminin Chain Affects Differentiation of Colorectal Cancer Cells and Their Sensitivity to Chemotherapy. Biochimie (2020) 174:107-16. doi:10.1016/j.biochi.2020.04.016

31. Kuhn E, Kurman RJ, Soslow RA, Han G, Sehdev AS, Morin PJ, et al. The Diagnostic and Biological Implications of Laminin Expression in Serous Tubal Intraepithelial Carcinoma. American Journal of Surgical Pathology (2012) 36(12):1826-34. doi:10.1097/pas.0b013e31825ec07a 
32. Kunitomi H, Kobayashi Y, Wu RC, Takeda T, Tominaga E, Banno K, et al. LAMC1 Is a Prognostic Factor and a Potential Therapeutic Target in Endometrial Cancer. J Gynecol Oncol (2020) 31(2):e11. doi:10.3802/ jgo.2020.31.e11

33. Zhang Y, Xi S, Chen J, Zhou D, Gao H, Zhou Z, et al. Overexpression of LAMC1 Predicts Poor Prognosis and Enhances Tumor Cell Invasion and Migration in Hepatocellular Carcinoma. J Cancer (2017) 8(15):2992-3000. doi:10.7150/jca.21038

34. Zhou J, Zhang Y, Han Z, Dong Z, Cao T, Wei A, et al. miR-506 Contributes to Malignancy of Cutaneous Squamous Cell Carcinoma via Targeting of P65 and LAMC1. Cell Cycle (2019) 18(3):333-45. doi:10.1080/15384101.2019.1568747

35. Nishikawa R, Goto Y, Kojima S, Enokida H, Chiyomaru T, Kinoshita T, et al. Tumor-Suppressive microRNA-29s Inhibit Cancer Cell Migration and Invasion via Targeting LAMC1 in Prostate Cancer. Int J Oncol (2014) 45(1):401-10. doi:10.3892/ijo.2014.2437

36. Peng $\mathrm{X}, \mathrm{Yu} \mathrm{M}$, and Chen J. Transcriptome Sequencing Identifies Genes Associated with Invasion of Ovarian Cancer. J Int Med Res (2020) 48(9): 300060520950912. doi:10.1177/0300060520950912

37. Zhang D, Guo H, Feng W, and Qiu H. LAMC2 Regulated by microRNA-125a$5 \mathrm{p}$ Accelerates the Progression of Ovarian Cancer via Activating P38 MAPK Signalling. Life Sci (2019) 232:116648. doi:10.1016/j.lfs.2019.116648

38. Qiu L, Wang J, Chen M, Chen F, and Tu W. Exosomal MicroRNA-146a Derived from Mesenchymal Stem Cells Increases the Sensitivity of Ovarian Cancer Cells to Docetaxel and Taxane via a LAMC2-Mediated PI3K/Akt axis. Int J Mol Med (2020) 46(2):609-20. doi:10.3892/ijmm.2020.4634

39. Jiang $\mathrm{P}, \mathrm{He} \mathrm{S}, \mathrm{Li} \mathrm{Y}$, and $\mathrm{Xu} \mathrm{Z}$. Identification of Therapeutic and Prognostic Biomarkers of Lamin C (LAMC) Family Members in Head and Neck Squamous Cell Carcinoma. Med Sci Monit (2020) 26:e925735. doi:10.12659/MSM.925735
40. Huang D, Du C, Ji D, Xi J, and Gu J. Overexpression of LAMC2 Predicts Poor Prognosis in Colorectal Cancer Patients and Promotes Cancer Cell Proliferation, Migration, and Invasion. Tumour Biol (2017) 39(6): 1010428317705849. doi:10.1177/1010428317705849

41. Wang Y, Shi M, Yang N, Zhou X, and Xu L. GPR115 Contributes to Lung Adenocarcinoma Metastasis Associated With LAMC2 and Predicts a Poor Prognosis. Front Oncol (2020) 10:577530. doi:10.3389/fonc.2020.577530

42. Yang JL, Wang CCN, Cai JH, Chou CY, Lin YC, and Hung CC. Identification of GSN and LAMC2 as Key Prognostic Genes of Bladder Cancer by Integrated Bioinformatics Analysis. Cancers (Basel) (2020) 12(7):1809. doi:10.3390/ cancers 12071809

43. Li L, Shirkey MW, Zhang T, Xiong Y, Piao W, Saxena V, et al. The Lymph Node Stromal Laminin a5 Shapes Alloimmunity. J Clin Invest (2020) 130(5): 2602-19. doi:10.1172/jci135099

44. Simon T, Li L, Wagner C, Zhang T, Saxena V, Brinkman CC, et al. Differential Regulation of T-Cell Immunity and Tolerance by Stromal Laminin Expressed in the Lymph Node. Node (2019) 103(10):2075-89. doi:10.1097/ tp.0000000000002774

45. Kenne E, Soehnlein O, Genové G, Rotzius P, Eriksson EE, and Lindbom L. Immune Cell Recruitment to Inflammatory Loci Is Impaired in Mice Deficient in Basement Membrane Protein Laminin a4. J Leukoc Biol (2010) 88(3):523-8 doi:10.1189/jlb.0110043

Copyright (c) 2021 Diao and Yang. This is an open-access article distributed under the terms of the Creative Commons Attribution License (CC BY). The use, distribution or reproduction in other forums is permitted, provided the original author(s) and the copyright owner(s) are credited and that the original publication in this journal is cited, in accordance with accepted academic practice. No use, distribution or reproduction is permitted which does not comply with these terms. 